\section{Down to earth}

\section{Internationaler Geographenkongress in Köln}

Nach über 100 Jahren kam vom 26. bis 30. August 2012 der Weltgeographenkongress erneut nach Deutschland. Mehr als 2.300 Geographen aus 82 Ländern der Welt diskutierten auf dem Internationalen Geographenkongress $(\mathrm{IGC}=$ International Geographical Congress) unter dem Motto „Down to earth" hochrelevante Fragen der Menschheit. Neben führenden Wissenschaftlern waren Prof. Dr. Klaus Töpfer (ehem. Umweltminister und ehem. UNEPPräsident), Dr. Martin Lees (Club of Rome) und Prof. Dr. Eduardo de Mulder (International Year of Planet Earth der UNESCO) zu Gast und hielten Hauptvorträge. Veranstaltungsort war die Universität zu Köln.

Im Mittelpunkt standen die Kernthemen „Globaler Wandel und Globalisierung“, „Mensch-Umwelt-Forschung“, "Risiko- und Konfliktforschung“", „Urbanisierung“ sowie „Demografischer Wandel". Die Themen wurden in den Hauptvorträgen im Überblick angesprochen. In mehr als 400 Fachsitzungen ging es vertieft um Fragen wie: Welche Auswirkungen hat der Globale Wandel auf unsere Umwelt und Gesundheit? Welche Maßnahmen können vor Naturkatastrophen schützen? Wie kann die nachhaltige Stadt der Zukunft aussehen?

Veranstalter des alle vier Jahre stattfindenden Kongresses ist die International Geographical Union (IGU); Ausrichter war 2012 die Deutsche Gesellschaft für Geographie (DGfG). Die lokale Organisation des Weltkongresses lag in den Händen des Geographischen Instituts der Universität zu Köln unter der Leitung der Geographie-Professorin
Gastgeberstadt des IGC 2012: Köln (Foto (C) Rike / Pixelio)

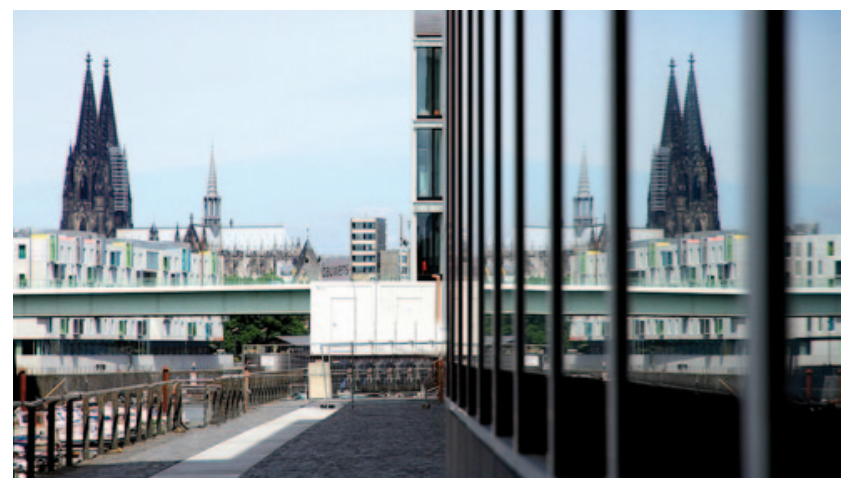

Frauke Kraas und des Geographie-Professors Dietrich Soyez, beide Universität Köln.

Geographen schlagen mit ihrer Ausrichtung auf Physische Geographie und Humangeographie eine wichtige Brücke zwischen Natur- und Sozialwissenschaften. In diesem Spannungsfeld gilt es Antworten auf den globalen Wandel zu finden. So hat die Menschheit bereits weitreichend in die Natur eingegriffen. „Es ist unstrittig: Der Einfluss der Menschen hat stark zugenommen - qualitativ und quantitativ. Es ist Aufgabe der Geographen, die Ursachen zu erkennen und sie zusammen mit anderen Wissenschaftlern und der Öffentlichkeit zu bewältigen“, kommentierte Prof. Dr. Klaus Töpfer, Direktor des Institute for Advanced Sustainability Studies (Potsdam), den Kongress.

Anne Glover, wissenschaftliche Hauptberaterin der EU-Kommission, rief die Geographen dazu auf, sich öffentlich und bei Politikern Gehör zu verschaffen: „Die Menschheit steht vor großen Herausforderungen, bei deren Lösung die Politik den Input von Forschern benötigt, insbesondere von Geographen, denn sie sind mit ihrem breiten Spektrum prädestiniert für diese Aufgabe." Glover begrüßte die Geographen stellvertretend für den Schirmherren des IGC 2012, Martin Schulz, Präsident des Europäischen Parlaments, auf der Eröffnungsveranstaltung des IGC.

\section{Gut besuchte DVAG- Veranstaltungen}

Auch der DVAG war in Köln dabei und hat „Angewandten Wind“ auf den IGC gebracht. Vertreter des Verbandes erweiterten den ansonsten sehr auf die Ergebnisse der Forschung ausgerichteten Kongress ein praktische Note. Vier gut bis sehr gut besuchte Sitzungen, zeigten erneut, wie wichtig es ist, angewandt geographische Fragestellungen auch im Rahmen der großen Wissenschaftskongresse zu erörtern:

- Angewandte Geographie im 21. Jahrhundert: Praxisrelevanz der Geographie in Politik, Wirtschaft und Gesellschaft,

- Geographen und ihr Markt - (internationale) Berufsperspektiven für Bachelor- und Master-Studierende,

- Angewandte Geographie und Entwicklungszusammenarbeit,

- „Vom Studium zum Job“ - Praxistipps zum Berufseinstieg.

Eine Exkursion zum Thema „2000 Jahre Stadtentwicklung in Köln" rundete das Engagement des DVAG auf dem IGC ab. 